An International elournal of Prehospital Care Research, Education, clinical Practice, Policy and Service Delivery ISSN 1447-4999

\title{
EDUCATION
}

\section{Evaluation of Medical Students in the training of Paediatric Life Support}

- A Spanish Perspective

Article 990052

\author{
Patricia Aparicio MD* \\ Jesús López-Herce MDPhD* \\ Angel Carrillo MDPhD* \\ Luis Sancho MD* \\ Ramón Moral MD*
}

*Paediatric Intensive Care Unit, Gregorio Marañón Hospital, Complutense University of Medicine, Madrid, Spain

\section{Summary}

Objective: To determine the usefulness of a training programme in paediatric basic cardiopulmonary resuscitation for $5^{\text {th }}$ and $6^{\text {th }}$ year medical students.

Methods: For the past eight years, the Faculty of Medicine of the Complutense University in Madrid has been offering formal training in paediatric cardiopulmonary resuscitation (CPR) to its students. We have analysed the results of 8 basic paediatric cardiopulmonary courses with 527 students, comparing scores in written tests consisting of 10 or 20 multiple-choice questions, administered before and at the end of the courses, while also undertaking a practical test on basic cardiopulmonary resuscitation skills in infants and children. The course was evaluated by the students by means of an anonymous written questionnaire.

Results: The mean initial score (out of a maximum of 10) was $6.03 \pm 1.58$ (maximum 10, range 2-10), whereas in the final test it was $9.59 \pm 0.68$ (range $5-10)(p<0.001)$. The majority of these students acquired theoretical knowledge (97.2\%) and adequate practical skills (93\%) in paediatric basic cardiopulmonary resuscitation. They were generally satisfied with the lectures, practical training and ability of the teaching staff.

Conclusions: The paediatric basic life support course is a useful method for theoretical and practical training. Paediatric cardiopulmonary resuscitation should be included in the medical training curriculum.

\section{Keywords:}

Education; medical students; curriculum; paediatric training; basic life support

\section{INTRODUCTION}

The prognosis in respiratory and cardiac arrest depends on several factors: the cause of the arrest, the previous state of the victim, the speed and efficacy of cardiopulmonary resuscitation (CPR) and the efficacy of transportation and later support.(1,2) Although much has been improved, there has been little change in the prognosis of paediatric cardiac arrest. $(1,2)$ This is thought to be due to the late initiation of CPR. When basic life support starts (BLS) within the first four minutes after arrest and advanced life support starts within the following 8 minutes, the prognosis is greatly improved.(3,4) Most respiratory and cardiac 
arrests occur out of hospital, which means that it is very important to educate medical professionals and the general public in BLS, since it is the first link in the survival chain. $(3,5)$

The formal training of medical students in CPR is important for at least two reasons: physicians must be able to perform CPR on all types of patients in any situation, and they must also take a role in passing this knowledge on to paramedical workers and lay persons. CPR cannot be learned just by reading or listening to theoretical concepts, practice is essential. For ethical reasons, this should be carried out on mannequins because, in the event of sudden death, CPR must be performed by the most experienced people available.(5,6) The number of participants in each practical course needs to be limited, in order to enable everyone to acquire the necessary skills in BLS. Depending on the course and population (lay persons or health care professionals) the optimum number of students at each skill station is of 4 to 8. This number allows practice to be carried out for a sufficient time to achieve adequate skills in resuscitation manoeuvres.(6,7)

As we offer formal training in basic CPR to medical students, the aim of this study is determine whether our training programme provides students with adequate skills and knowledge in CPR.

\section{MATERIALS AND METHODS}

Paediatric CPR courses at the Faculty of Medicine in the Complutense University of Madrid are taught by personnel from the paediatric intensive care unit at the Gregorio Marañón Hospital, and are designed for $5^{\text {th }}$ and $6^{\text {th }}$ year medical students. In order to assess the success and efficacy of our training programme, we have analysed the results of 8 paediatric basic life support courses for medical students.

The courses in our study were of 6 hours duration over two days, covering theoretical and practical skills. $35 \%$ of the time was dedicated to lectures, $50 \%$ to practice on mannequins, and the remaining $15 \%$ to evaluating the efficacy of the training. The two theoretical lectures, covered topics in first aid, vital functions and signs, prevention and basic life support, based on the recommendations of the International Guidelines and the Spanish Group for Paediatric and Neonatal Resuscitation.(4,6) Practical training is organised around two skill stations (infant and child basic resuscitation). The infant mannequin was "Resusci Baby" (Laerdal ${ }^{\circledR}$ ) and the child mannequin was "Danny" (Medical Plastic ${ }^{\circledR}$ ).

Students were divided into groups of 6 to 8, each with one teacher and one or two mannequins. All students perform BLS at the infant and child skill stations. Each student first performs each CPR manoeuvre several times and the instructor corrects any errors. Later the instructor presents a hypothetical scene and the students have to perform CPR uninterrupted in this simulated clinical situation. The students had to take part in their own evaluation and in the performance evaluation of their classmates, providing critical feedback.

Before beginning the training, all the students sat a written exam consisting of 20 multiplechoice questions, dealing with basic life support (in the first two courses the theoretical test had only 10 questions). At the end of the course students sat the same exam again. The theoretical test was evaluated on a scale of 0 to 10 points. More than $80 \%$ correct answers were required (8 points) in order to pass the exam. Practical proficiency was also evaluated during and at the end of the course with a scale of 1-5 points being used to assess each of the following skills: recognition of unconsciousness and observation of vital functions, (b) calling for appropriate help, (c) airway opening, (d) mouth-to-mouth ventilation, (e) manual chest compression, (f) coordination of skills (Table 1). This scale has been approved by the Spanish Group for Paediatric and Neonatal Resuscitation and is used for basic and advanced 
cardiopulmonary resuscitation courses in paediatrics (7). A score of 3 was required for the student to pass the test. When any student did not pass the test, they were supposed to repeat it until they were successful.

Table 1. Practical evaluation criteria.

1. Do not perform the manoeuvre or perform it badly.

2. Perform the manoeuvre with serious errors, in an incorrect order or taking an excessive amount of time.

3. Have some problems performing the manoeuvre, need several attempts or carry it out more slowly than required.

4. Perform the manoeuvre correctly with minor defects.

5. Perform the manoeuvre well at an acceptable rate and rhythm.

After the exams, the students evaluated how effective they had found the training courses by answering an anonymous questionnaire on the content and format of the lectures, practical training and teachers' ability based on a scale of 1 to 5 points ( 1 very poor, 2 poor, 3 adequate, 4 good, 5 very good).

The data was analysed using the SPSS statistical programme version 10 for Windows, and is presented as percentages and means \pm standard deviation. Statistical analysis of the initial and final theoretical examinations was carried out using the ANOVA and Bonferroni test. Comparison between groups was carried out using Student's t test. A value of $p<0.05$ was considered to indicate statistical significance.

\section{RESULTS}

The total number of students was 527: 113 in the first course, 75 in the second, 53 in the third, 61 in the fourth, 68 in both the fifth and sixth courses, 51 in the seventh and 38 in the eighth (Figure 1). There were only 38 students in the last course because of fewer fifth year students in our hospital that year. For all the students it was their first CPR-BLS training course.

\section{Figure 1. Number of students per course}

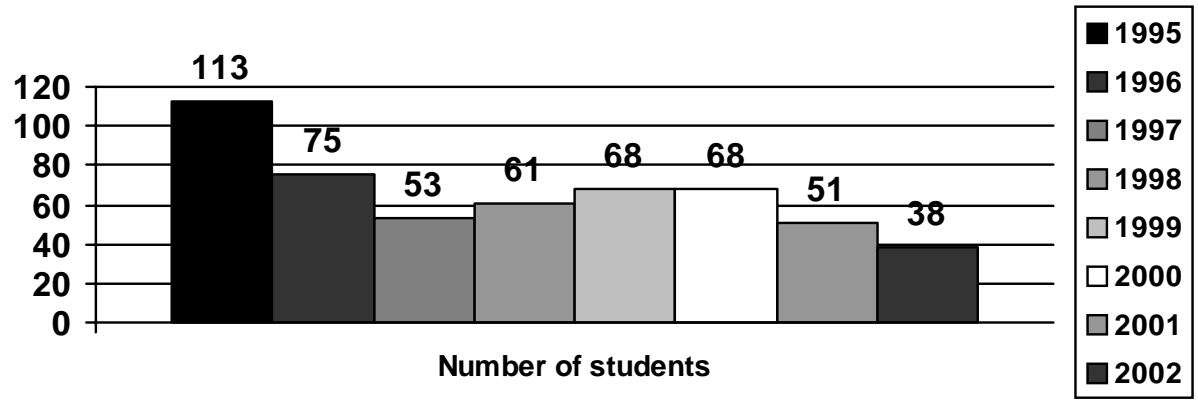


The mean score in the written test before the course was $6.03 \pm 1.58$ (maximum 10, range 2 10 ), and in the final test was $9.59 \pm 0.68$ (range $5-10$ ). The difference between these scores was statistically significant $(\mathrm{p}<0.001)$. Table 2 shows the comparison between the scores of the first and final examinations by years. The difference was statistically significant $(\mathrm{p}<$ $0.001)$.

Table 2. Comparison between first and final exam scores by years

$\begin{array}{lcccccccc} & 1995 & 1996 & 1997 & 1998 & 1999 & 2000 & 2001 & 2002 \\ & & & & & & & & \\ \text { Initial score } & 7.12 & 6.78 & 5.46 & 4.82 & 5.22 & 5.73 & 6.10 & 6.05 \\ \text { Final score } & 9.71 & 9.59 & 9.13 & 9.77 & 9.74 & 9.64 & 9.33 & 9.49 \\ \mathrm{p}<0.001 \text { all years } & & & & & & & \end{array}$

Comparison of the scores of the multiple-choice question exams with 10 and 20 questions shows a higher mean score in the first exam with 10 questions, $6.98 \pm 1.64$, compared to the 20-question exam, $5.51 \pm 1.29$ ( $\mathrm{p}<0.001$ ), but there was no difference between the scores of the final 10-question exam, $9.66 \pm 0.56$, and the final 20-question exam, $9.55 \pm 0.74$ (Table $3)$. The percentage of students who achieved a score of over $80 \%$ correct answers was higher in the final exam, $97.2 \%$, than in the initial exam, 14.9\%. A total of $93 \%$ of students passed the skills' tests (score $>3$ ). Scores were higher for the practical CPR skills on children, $3.86 \pm$ 0.62 , than on infants, $3.64 \pm 0.63(\mathrm{p}<0.001)$.

Table 3. Comparison of scores in the theoretical test by number of questions

\begin{tabular}{|c|c|c|c|}
\hline \multicolumn{2}{|c|}{ Number of questions } & Mean & Standard deviation \\
\hline Initial test & 10 & 6.99 & 1.64 \\
\hline & 20 & 5.52 & 1.28 \\
\hline Final test & 10 & 9.66 & 0.56 \\
\hline & 20 & 9.55 & 0.74 \\
\hline
\end{tabular}

The analysis of the questionnaires on the courses showed that students found them useful. In the students' evaluation (on a scale of 1 - 5), theoretical lectures received a score of $4.41 \pm$ 0.47 , the way they were taught a score of $4.41 \pm 0.47$, and practical training, $4.77 \pm 0.36$. The majority of students considered that they had acquired sufficient knowledge and skills to begin CPR-BLS when needed (85.3\%), but this percentage was lower than the final written exam score of $97.2 \%$, and lower than the practical evaluation percentage of $93 \%$. Medical students considered education in basic life support to be an essential part of their curriculum in paediatrics. 


\section{DISCUSSION}

Respiratory and cardiac arrest in children and paediatric resuscitation are different from arrest and resuscitation in adults. They are far more common during the first year of life than later $(1,2)$. Cardiac arrest in children is usually the result of hypoxaemia and acidosis due to respiratory insufficiency, neurological disorders or shock. Causes vary according to age: sudden death and respiratory infections in the first year of life and road traffic accidents in children and adolescents. For anatomical and physiological reasons, cardiopulmonary resuscitation methods are different for neonates, infants and children $(4,6)$. Consequently, when teaching paediatric resuscitation, it is very important to emphasise the identification of apnoea and ventilation technique.

Currently, basic paediatric cardiopulmonary resuscitation is often not taught as well as in adults, not only to the general public, but also to medical professionals (7-11). Preventive measures, such as child-resistant closure systems for drug containers, have already proven effective in preventing arrest in children. This means that we also have to improve paediatric resuscitation teaching (12-13).

It is already widely accepted that education in paediatric resuscitation must be achieved through practical training courses, since the acquisition of skills is more important than theory $(12,13)$. In Spain, CPR-BLS teaching is designed for medical students, medical and paramedical professionals and parents with "high risk" children, and the present aim is to reach the lay public, since anyone can find themselves in the situation of being the first helper in sudden arrest cases outside hospitals (4). Education in CPR should be a regular part of the curriculum in schools, as teaching CPR-BLS can lead to lives being saved.

Although a number of studies have reported the results of basic and advanced CPR training for medical students $(9,10,14)$, there are no studies which analyse the efficacy of specific basic paediatric cardiopulmonary resuscitation training for medical students. The results of our study indicate that a great majority of our students are successful at the written examinations and practical tests. Tests at the beginning of the courses inform us of the previous knowledge of students whilst the final test indicates newly acquired knowledge and skills; comparison of the two tests reflects the efficacy of the training courses. The 20 multiple-choice question exam appears to be better than the 10-question exam when it comes to evaluating the effectiveness of the courses. By asking students about the quality and effectiveness of the training course and for their suggestions for subsequent CPR courses, we are continually able to improve our programme. Despite their scores being high, students still feel apprehensive when contemplating the possibility of dealing with a critically ill patient, thus bringing to our attention the importance of refresher courses. Thanks to the questionnaire about the training courses, we are aware that students find them interesting and useful.

Other methods for CPR education are viable (books, television programmes, practice demonstrations without practical training on mannequins, videos and individual practice with mannequins without instructor evaluation) (14-17). Although all methods can be useful, we believe that individual practice with feedback from an instructor is the best method for teaching CPR as this method allows errors to be corrected and enables the knowledge acquired to be consolidated. It is important that students practice individually on a nearly-real simulation scene at the skill station, and this can only be achieved with an instructor. The student also learns from observation as each member of his group practises and by participating in the evaluation.

With regard to external cardiopulmonary resuscitation/basic life support in children, there is still much to be done in Spain. As resuscitation medicine is a multidisciplinary practice, we 
need to improve our education in all links of the survival chain. One of the limitations of our study is that we have not assessed how much of the knowledge and skills acquired have been retained 6 to 12 months after the course. We agree with reports in the literature on the poor retention of CPR knowledge and skills emphasising the importance of re-training, as well as the need for refresher courses and continuous education $(3,18,19)$.

Based on our results, education in paediatric cardiopulmonary resuscitation must form a part of the curriculum in medical training. CPR programmes such as ours are necessary to provide students with a solid basis in emergency medicine. Our study only analyses newly acquired

CPR knowledge and skills. Further studies are needed to evaluate retention of this knowledge and skill after 6 and 12 months and to compare the different methods of CPR education for medical students.

\section{REFERENCES}

1. Schindler MB, Bohn D, Cox PN, et al. Outcome of out-of-hospital cardiac or respiratory arrest in children. $N$ Engl J Med 1996; 335:1473-1479.

2. Kuisma M, Suominen P, Korpela R. Pediatric out-of-hospital cardiac arrest: Epidemiology and outcome. Resuscitation 1995;30:141-150.

3. Guidelines 2000 for Cardiopulmonary Resuscitation and Emergency Cardiovascular Care. Introduction to the international guidelines 2000 for CPR and ECC: A consensus on Science. Circulation 2000;102 (suppl I):1:1-11.

4. Guidelines 2000 for Cardiopulmonary Resuscitation and Emergency Cardiovascular Care. Pediatric basic life support. Circulation 2000;102 (suppl I):9: 253-290.

5. Safar P, Bircher NG. Enseñanza de los primeros auxilios y reanimación. En Reanimación cardiopulmonar y cerebral. Ed Interamericana, Madrid. 1988; 371-382.

6. Calvo C, Rodríguez A, López-Herce J, y Grupo Español de Reanimación Cardiopulmonar Pediátrica y Neonatal. Recomendaciones de Reanimación Cardiopulmonar Pediátrica y Neonatal (II).Reanimación cardiopulmonar básica en pediatría An Esp Pediatr 1999;51:409-416.

7. Carrillo Álvarez A, López-Herce Cid J, Moral Torrero R, et al. Evaluación de los cursos de reanimación cardiopulmonar básica y avanzada en pediatría. An Esp Pediatr 2000; 53: 125-134.

8. López-Herce J, Carrillo A, Sancho L, et al. Conocimientos teóricos de reanimación cardiopulmonar de los médicos residentes de pediatría y cirugía pediátrica. An Esp Pediatr 1995;43:257-260

9. Liberman M, Golberg N, Mulder D, et al. Teaching cardiopulmonary resuscitation to CEGEP students in Quebec-project. Resuscitation 2000; 47: 249-257.

10. Starc B, Pecan M. Training of medical students in resuscitation at the University of Ljubljana. Resuscitation 1996; 32: 19-22.

11. García-Barbero,M., Caturla-Such, J. What are we doing in cardiopulmonary resuscitation training in Europe? An analysis of a survey. Resuscitation 1999; 41: 225-236.

12. López-Herce J, Carrillo A, Sancho L, et al. Paediatric basic and advanced life support courses: first experience in Spain. Resuscitation 1996;33:43-48.

13. Chameides L. Cardiopulmonary resuscitation: standards, guidelines, and education. Pediatrics. 1987;79:446-449.

14. Clark LJ, Watson J, Cobbe SM, et al. CPR'98: a practic multimedia computer-based guide to cardiopulmonary resuscitation for medical students. Resuscitation 2000; 44: 109117.

15. Braslow A, Brennan RT, Newman MM, et al. CPR training without an instructor: development and evaluation of a video self-instructional system for effective performance of cardiopulmonary resuscitation. Resuscitation 1997:34:207-220. 
16. Eisenberg M, Damon S, Mandel L, et al. CPR instruction by videotape : results of a community project. Ann Emerg Med 1995;25:198-202.

17. Todd KH, Braslow A, Brennan RT, el al. Randomized, controlled trial of video selfinstruction versus traditional CPR training. Ann Emerg Med 1998;31:364-369.

18. Kaye W, Mancini ME. Retention of cardiopulmonary skills by physicians, registered nurses and the general public. Crit Care Med 1986;14:620-622.

19. Kaye W, Rallis SF, Mancini ME, et al. The problem of poor retention of cardiopulmonary resuscitation skills may lie with the instructor, not the learner or the curriculum. Resuscitation 1991; 21:67-87. 